\title{
Social Justice in Practice? Exploring Teacher Candidates' Commitment Toward Change Agency Through Action Research
}

\author{
Stephanie L. Burrell Storms \\ Fairfield University, sstorms@fairfield.edu
}

Follow this and additional works at: https://digitalcommons.fairfield.edu/education-facultypubs Copyright 2015 Taylor and Francis. A post-print has been provided with permission from the copyright holder. The final publication is available at Taylor and Francis via http://dx.doi.org/ 10.1080/01626620.2015.1004600

\section{Peer Reviewed}

\section{Repository Citation}

Burrell Storms, Stephanie L., "Social Justice in Practice? Exploring Teacher Candidates' Commitment Toward Change Agency Through Action Research" (2015). GSEAP Faculty Publications. 122. https://digitalcommons.fairfield.edu/education-facultypubs/122

\section{Published Citation}

Burrell Storms, Stephanie. "Social Justice in Practice? Exploring Teacher Candidates' Commitment Toward Change Agency Through Action Research." Action in Teacher Education 37.2 (May 18 2015): 156-171. DOI:10.1080/ 01626620.2015 .1004600

This item has been accepted for inclusion in DigitalCommons@Fairfield by an authorized administrator of DigitalCommons@Fairfield. It is brought to you by DigitalCommons@Fairfield with permission from the rightsholder(s) and is protected by copyright and/or related rights. You are free to use this item in any way that is permitted by the copyright and related rights legislation that applies to your use. For other uses, you need to obtain permission from the rights-holder(s) directly, unless additional rights are indicated by a Creative Commons license in the record and/or on the work itself. For more information, please contact digitalcommons@fairfield.edu. 
Social justice in practice? Exploring teacher candidates' commitment toward change agency through action research

Scholars argue that graduates from teacher preparation programs are ill-prepared to teach an increasingly diverse student population (e.g., race/ethnicity, language, sexual orientation) (Colón-Muñiz, Brady, \& SooHoo, 2010). Likewise, teachers have questioned their ability to effectively teach students from diverse backgrounds (Ladson-Billings, 2011). These concerns combined with a persistent achievement gap among black, Latino, and white students (NCES, 2009) require teacher educators to prepare teachers who are culturally responsive (Gay, 2010), reflect on their teaching decisions, assess the outcomes of their practice (Harris, Bruster, Peterson, \& Shutt, 2010), and advocate for social justice in schools and schooling (Kaputska, Howell, Clayton, \& Thomas, 2009).

In the teacher education program where I teach, we aim to prepare teacher candidates who act as change agents for social justice through education. One way I prepare candidates for this role is through conducting action research (AR) (also referred to as participatory research or teacher research), a systematic approach to inquiry that provides teachers with a process to reflect on and study their own practice to improve student learning and solve issues related to schools and schooling (McNiff \& Whitehead, 2010). Some scholars have criticized teacher education programs for using AR to improve teachers' technical skills or practical knowledge rather than achieve its emancipatory goals (Carr \& Kemmis, 2009; Cochran-Smith \& Lytle, 2009; Kinsler, 2010). When teaching AR, I often struggle with the tension of supporting candidates' choice to pursue non-emancipatory research they deem meaningful and challenging them to pose questions that examine social injustice in education (Burrell Storms, 2013; Valli \& Price, 2005). Critical AR has been identified as way to reconnect teaching practice to social 
justice goals in education (Manfra, 2009a) and I contend that teacher candidates who engage in critical AR show a developing commitment toward change agency. In this paper, I explore how teacher candidates' AR projects in a graduate-level course demonstrate (or not) the principles of critical AR. I begin by framing the paper with critical AR as a transformative teacher education approach that has the potential to prepare candidates to advocate for social justice.

\section{Theoretical Framework}

I use Manfra's framework (2009a) as a lens to analyze how teacher candidates' AR projects reflect a practical or critical approach to AR. Manfra's framework draws on the work of scholars who advocate for a practical (e.g. Falk \& Blumenreich, 2005, Gall, Gall, \& Borg, 2007) or critical approach to AR (e.g, Carr \& Kemmis, 2009, Cochran-Smith \& Lytle, 2009). Practical AR focuses on improving the technical skills of the teacher (e.g. classroom assessment) and exploring the daily practice and concerns of the educator. The focus of change is the classroom rather than institutions or society. The goal of practical AR is to conform to and implement state, local, or federal policies (e.g., Common Core State Standards) without critique; is driven by the needs of one person; and privileges the voices of "experts" over those with less power (Kemmis, 2006). This approach "may result in improved practice and student performance, but not social and cultural change" (Manfra, 2009a, p. 41).

Alternately, critical AR examines social and cultural factors that may affect schooling (e.g., poverty, racism, cultural knowledge) and help teachers develop a more complex understanding of their students' lives. Students' lived experiences, cultural backgrounds, and prior knowledge is valued, viewed as strengths, and an authentic and relevant course of inquiry (Burrell Storms, 2013). It encourages democratic practices in schools to give key stakeholders voice (e.g. students, families) and builds on their ability to critically reflect and interrogate 
structural inequality in schools and schooling to foster empowerment (e.g. funding distribution). Lastly, critical AR engages in social action within and outside schools - in addition to exploring practical issues of teaching and learning. Teacher candidates who conduct critical AR use inquiry to understand how schooling and schools can interfere with marginalized groups' ability to be successful academically; connect classroom level experiences to broader social and political issues (Daoud, 2010); and engage in actions to remove those barriers. Socially just schools develop authentic relationships with all key stakeholders, endorse their full participation in all aspects of schooling and schools, and redistribute power and resources to promote their success in school and society. I argue critical action research is one form of action that can help us work toward these goals.

One of the criticisms of critical AR is that it may undervalue the importance teachers place on day-to-day issues of practice instead of acknowledging "the reality [that] classroom life is mutually steeped in practical and critical concerns" (Manfra, 2009a, p. 41). A challenge for teacher educators is getting teachers to see classroom inquiry as integral to the daily teaching and learning process, and not an add-on.

The number of studies exploring teachers' and teacher candidates' engagement in critical AR and their developing commitments toward change agency is limited. The following studies show teachers and teacher candidates conducting critical AR projects and engaging in change agency activities. For example, pre-service and practicing teachers conducted AR projects that examined social and cultural factors that may influence schooling such as the impact of social class on community institutions (e.g. libraries) (Martin, 2005); teacher collaboration to meet the needs of diverse learners (Church, 2010); use of differentiation and culturally responsive pedagogy to increase students' academic performance (Manfra, 2009b); use of empowering 
science pedagogy in a high-poverty urban school (Furman, Barton, \& Muir, 2012); literacy instruction for ELLs (Sowa, 2009; Razfar, 2011); instruction at a faith-based school in a rural area (Kane \& Chimwayange, 2014); and exploring the achievement gap for ELLs and African American students (Jacobs, Yamamura, Guerra \& Nelson, 2013). As a result of conducting critical AR, pre-service and practicing teachers reported actions such as engaging in culturally responsive teaching (Furman, Barton, \& Muir, 2012, Manfra, 2009b); implementing democratic practices in the classroom (Furman, et al., 2012, Kane \& Chimwayange, 2014, Sowa, 2009); developing meaningful relationships with communities of color (Jacobs, et al., 2013); developing a model to increase teacher collaborations to meet diverse learners needs (Church, 2010); and participating in activism related to their AR projects (Martin, 2005; Razfar, 2011). However, more research is needed to understand how teacher candidates' experiences with conducting AR have the potential to deepen their commitments toward acting as change agents.

In this study, I used the following questions to explore how candidates' AR projects reflect (or not) critical AR and a commitment toward change agency: (1) What are the AR topics teacher candidates pose? (2) What actions do teacher candidates report (or intended actions) as a result of conducting AR during and after the course? (3) How do teacher candidates' research topics, reasons for their choices, and actions they report demonstrate (or not) critical AR and a developing a commitment toward change agency? In what follows, I provide a description of the AR course and present the methods, findings, and implications from this investigation.

\section{Methods}

\section{Context for the Study}

Researcher Positionality. I am an African-American woman and have been a teacher educator for five years. I designed the AR course and have taught it five times since its inception 
in Spring 2008. As the instructor and participant researcher, I bring to the study of this course the belief that through education, collaboration, and action, citizens can reduce structural inequality and increase equity in social institutions, including schools. Conducting AR in a local urban school as a teacher educator has shown me the challenges and transformative benefits of AR. My goal in teaching and studying this course is to explore and document how AR might prepare candidates for roles as change agents for equity and social justice through education. I believe social justice goals and accountability are important when preparing teachers to work in schools with an increasingly diverse student population.

This study, approved by the University's Institutional Review Board, takes place at a private Jesuit institution in the northeast and draws on teacher candidates' experiences in an AR course required for those enrolled in our Master's degree program for experienced educators seeking advanced training. The majority of the candidates are teachers; however, some are community educators. Our candidates are predominantly white, Catholic, female, from upper middle/upper class families and live primarily in suburban areas (Boczer, Wrinn, \& Nash, 2013). The program graduates approximately 10 students per year. The 15 -week AR course has an enrollment of six to eight students. The primary goal of the course is to teach candidates research skills needed to conduct socially responsible research and advocacy projects to improve students' learning and/or the lives of the community members where they work.

Course description. In a previous study I conducted, teacher candidates indicated that conducting research that is meaningful and relevant to their lives; critically reflecting on their practice; learning a process for change; and being involved in a collaborative, participatory, and supportive classroom community were key factors in preparing them for social justice advocacy (Burrell Storms, 2013). Therefore, I provide this course description to illustrate how I attempt to 
prepare candidates as change agents through critical AR and add to the literature on pedagogical approaches used in AR courses (Grossman, 2005).

During the first six weeks of the course we focus on the principles of critical AR, research design, and research ethics. Teacher candidates select their topics within the first three weeks of the semester, have seven to eight weeks to conduct their AR projects, and prepare a poster to present during the last week of the course. Candidates are required to read and critique articles (e.g., Souto-Manning, Mitchell, Cochran-Smith) and a textbook (Action Research in Education, Stringer, 2008) that describe practical and emancipatory approaches to AR in a variety of contexts using qualitative and quantitative methods. Many of the projects described in the readings focus on social justice issues, such as developing inclusive practices in schools, youth empowerment, sexual harassment, and improving home-school communication, with the goal of increasing candidates' sociocultural consciousness and helping them understand the need for change.

The assignments are cumulative (introduction to research paper, literature review, conducting research, AR report, and poster session) and candidates are required to facilitate one class discussion based on assigned reading. Early in the semester I do an exercise with candidates to help them explore the meaning of social justice and discuss how their projects reflect this concept. Candidates' AR topics are self-selected and they can work alone or with a partner to conduct their research.

To help students learn how to conduct AR I use the "look" (observation/gathering data), "think" (reflection/analyzing data), and "act" (action/reporting findings) framework (Stringer, 2008, p. 37). For instance, during the "look" phase students provide one another with feedback on their data collection methods (e.g. surveys, interview protocol). During the "think" stage, we 
discuss and practice data analysis techniques such as coding observation notes. During the "act" phase teacher candidates share what actions they have taken or plan to take as a result of conducting AR.

A weekly "check-in" is conducted at the beginning of every class to provide candidates with time to ask for help with an issue that arose during the inquiry process. Class discussions occur in small and whole groups and focus on assigned readings and the research process. Lectures are given at the end of class sessions to reiterate key information.

\section{Participants}

A purposeful, convenience sample was used for this inquiry (Patton, 2002). Ten teacher candidates who were enrolled in the AR course during Spring 2010 and 2011 semesters agreed to participate in this study. Six of the participants were practicing teachers and three were completing internships. One candidate was unemployed. Four candidates taught in public, urban schools and two in private, suburban schools. After course completion and graduation, five taught in elementary schools, three in middle schools, one in high school; the remaining participant pursued educational policy work. Six females and one male identified as white/Caucasian. One female identified as Asian and another as Hispanic. In addition, one female identified as "other." The majority of the teacher candidates were in their twenties, two were in their thirties and one was in her/his fifties.

\section{Data Collection}

I used an ethnographic approach to data collection that involved gathering multiple forms of qualitative data including student artifacts, interviews, and participant observation (Creswell, 2007; Charmaz, 2010). The following data were collected from the Spring 2010 and 2011 courses: candidates' work samples (introduction to research paper, literature reviews, and final 
report); semi-structured interviews; and my own observation notes during and after class sessions. The introduction to research paper was candidates' first time to discuss the driving research questions for their studies and why it is an authentic and relevant course of inquiry. In the literature reviews, I paid close attention to how they contextualized their studies in relation to existing literature. I also used candidates' final reports to explore actions they reported (or intended actions) as a result of conducting their studies during the course.

After gaining consent to interview each candidate, I conducted semi-structured interviews in Fall 2011 to compare and contrast candidates' intended actions as reported in their final reports with those they actually took after the course ended. The interviews were approximately 60-90 minutes and took place in my office on campus or at the home of the teacher. The openended interview protocol (see appendix A) elicited candidates' experiences conducting AR during the course and actions taken as a result of their experiences. I drew on observation notes from class discussions and activities to triangulate data from participants' written assignments and interviews.

\section{Data Analysis}

Grounded theory protocols were used for data analysis (Charmaz, 2010). I conducted a content analysis of candidates' work samples to explore how their projects reflected critical AR. Qualitative content analysis is used to interpret the meaning of text data through the process of coding and identifying patterns and themes (Hsieh \& Shannon, 2005, Zang \& Wildemuth, 2009). Conventional content analysis is "appropriate in studies where the research literature about a particular phenomenon is limited" (Hsieh \& Shannon, 2005, p.1279). I began the content analysis by reading the introduction to research papers and literature reviews to understand candidates' reasons for the research questions they posed. Through several reading of the papers, 
I highlighted significant statements that revealed their reasons for the research questions posed (Hsieh \& Shannon, 2005). When reading the final reports, I focused on their reported actions or actions they planned to take after the course. Next, I used the constant comparative method and open coding to assign labels to the highlighted data (e.g., classroom change, parent voice, teacher collaboration, gender) and develop themes for all work samples (Charmaz, 2010, Zang \& Wildemuth, 2009). I wrote memos throughout this process (Charmaz, 2010) to document patterns, themes and contradictions that emerged from candidates' responses about reported actions and written assignments. I applied the same process to the interview transcripts to further explore their reasons for selected topics and related actions reported. Finally, I reviewed my observation notes from class discussions, activities, and candidates' presentations to further corroborate emerging themes. Six themes related to how candidates AR projects reflect (or not) critical AR (cultural identity, institutional structures, sociocultural factors, practical knowledge, choice, and voice) emerged from the analysis, which I reduced to three categories (cultural and institutional factors, emancipatory and practical reasons, and democratic practices) after I compared the themes to Manfra's framework (2009a).

Because I am the researcher and the instructor of the AR course my prior experiences could interfere with my ability to uncover nuances in the data. Therefore, I used several of Guba and Lincoln's (1982) recommendations to maintain trustworthiness. First, I engaged in peer debriefing with experienced teacher educators, qualitative researchers, or faculty who have conducted AR, to help with check-coding, alternative interpretations, and assessing the trustworthiness of the themes identified. In addition, all transcripts were sent to participants (member-checking) to edit before excerpts were included in this article because their exact wording is used. Only one teacher candidate asked for a minor revision (Change "and" to "the."). 
Lastly, I used multiple data sources to triangulate to candidates' commitment to change agency.

\section{Limitations}

One limitation of this study is the use of teachers' self-reports. Observation of their classroom teaching after they conducted AR would be a useful next step to confirm the findings in this inquiry. As such, the findings from this study may help us to understand the ways in which engagement in AR can indicate teachers' commitment to social justice advocacy, rather than their actual practices. Another limitation is that social justice is included in the mission of the institution and graduate school where this study takes place. So, it is possible that students' commitment toward social justice advocacy was developed or developing prior to conducting AR and the findings may be different at an institution where social justice is not included in the mission or practices of the university or college. Lastly, my sample was predominantly white and female. While this reflects the teaching population at large (National Center for Education Information, 2011), maximum variation sampling could have grounded my findings from patterns found through a diverse sample (Creswell, 2007).

\section{Findings}

The goal of this study was to explore how candidates' AR projects reflect (or not) the principles of critical AR that I argue indicate a commitment toward change agency for social justice in education. Three categories emerged from this inquiry. First, most of the teacher candidates explored topics focused on institutional and cultural factors that may impact students' academic achievement. Second, teacher candidates' motivations to pursue their topics were both practical and emancipatory. They were concerned with critical issues in education and improving their practice. Third, teacher candidates' reported actions (or intended actions) as a result of conducting AR was incorporating democratic practices into the teaching and learning process to 
empower key stakeholders. Categories one and three reflect the principles of critical AR while category two reflects both practical and critical AR. However, I believe the findings do indicate a developing commitment toward change agency. In what follows, I draw on representative data from participants' interviews and course assignments that illustrate how the themes demonstrate the ways in which participants' AR projects did or did not reflect critical AR.

\section{Cultural and Institutional factors}

Teacher candidates' AR projects focused on cultural identity issues such as gender, language, and parents' influence on student literacy, as well as institutional structures, such as curriculum standards or the relationships with special education teachers. The themes that emerged from the candidates' topic selections were cultural identity or institutional structures. Nine out of ten teacher candidates considered institutional (e.g., curriculum planning) or cultural (e.g., gender, identity) factors that may influence students' academic achievement (Table 1). For example, one team explored gender differences in classroom participation among ELLs. They wrote the following statement in the introduction to research paper:

In our experiences with English language learners, most students are leery to verbally participate in the classroom both socially and academically. However, this observation has been made considerably more often with female students than male students. This team decided to explore how social interactions among peers and with the teacher (reflecting on their own behavior) and cultural factors may play a role in what they observed in their classrooms. Other teacher candidates examined institutional structures connected to broader social and political issues such as standardized testing and school funding. For example, one teacher candidate decided to explore teachers' views on standards-based curriculum. In the 
introduction to research paper the candidate describes why this topic is a relevant course of inquiry:

I have long questioned whether teachers are satisfied with the approved curriculum objectives, goals and standards that must be carried out in the classroom. I consider [teachers' perspectives] on curriculum planning to be an authentic and relevant course of inquiry because it brings ideas of teacher accountability, student apathy, and top-down policy-making to the forefront.

Another team explored how gender differences may impact homework completion. At first, I found this example to be significant because exploring gender differences does indicate a consideration of a cultural factor. However, when I reflected on the purpose of their study further, I noticed the teachers were interested in techniques to encourage boys to do their homework rather than revealing an emancipatory goal for the study. Boys are seen as the barrier to their own academic achievement due to inappropriate behavior (resisting homework) instead of the structure of schooling. One of the teachers in this team wrote the following in the introduction to research paper:

As a teacher, it is frustrating when, after careful consideration and planning, students do not complete homework assignments. When I think about my own adolescent feelings about homework I can sympathize, even though I try to make the purpose of the assignment clear. I find that boys, more often than girls, tend to not complete their assignments.

In this example, the teacher does attempt to reflect on her/his own experience and feelings about homework to try to theorize why boys do not complete their homework. Gender is identified as a possible barrier to homework completion. However, the teacher's hypothesis is based on 
anecdotal evidence and her reflection about gender issues in the classroom was not emancipatory. Overall, the majority of the AR topics the candidates posed were connected to broader social and political issues in education that may provide them with a more complex understanding of their students and discover factors the can improve or interfere with their ability to be successful academically. With this information, teachers can take action to improve schooling. In the next section, I examine candidates' reasons for pursuing their topics to understand what lead to the questions posed and how the selections reflect (or not) a critical approach to AR.

\section{Emancipatory and practical reasons}

An analysis of the class assignments, interviews, and my observation notes provided insight into the issues that influenced participants' selected research topics. The candidates' reasons for topic selections reflect both a critical view of the social, cultural, and economic factors (e.g., funding reform) that influence unjust policies and practices in schools and schooling (Kemmis, 2006) and a need to increase their self-knowledge to improve their practice (e.g., "successful solutions" for increased homework completion) (Carr \& Kemmis, 2009). Eight out of 10 candidates' motivations to pursue their studies were both emancipatory and practical (Manfra, 2009a). The candidates, classroom discussion, papers, and interviews reveal a concern about inequality in schools and schooling and a desire to conduct research that could help them discover strategies to improve student achievement. For instance, an elementary teacher discussed her motivation to explore teachers' views about interventions in their classroom in the introduction to research paper:

Teachers are being given tasks to complete, but are not receiving training or implementing these new strategies. The question of a teacher's view on a proposed 
action that he or she is now expected to implement impacts everyone associated with the people involved. It is important to explore the teacher's viewpoint because his or her attitude and planning have a direct result on the community. It is evident that some classroom teachers are resistant to working with outside professionals. This may be caused by poor communication and lack of training for teachers to properly implement newly acquired strategies.

This teacher's motivation reflected critical AR in that she explored a social and cultural factor in schooling (i.e., effective relationships between general education and special education teachers and lack of training about students with special needs) that she believed affected how students received interventions in the classroom. The teacher's reasons are emancipatory. At the same time, the teacher wanted to explore techniques that would improve student learning in the classroom ("collaborative teaching can be mutually beneficial and result in more effective interventions for children with autism"). While changing techniques may increase student achievement, neither students' perspectives nor their parents voice was considered during data collection to help empower them during the process. The study focused on the perceived "experts" and their need for practical knowledge (Kemmis, 2006). Collaborating with students and parents could have led to broader change. In another example, a middle school teacher who explored how pop culture may influence student identity wrote the following in the introduction to research paper:

At the time, I was teaching The Outsiders, [where] the main theme is the importance of not wrongly stereotyping others. I thought about how much of an influence pop culture has on the way teens think, the way they act towards others and the way they perform in school. Stereotyping and prejudice are two things that happen constantly within a school 
environment. This is the time when students realize that they each have their own identity and begin to struggle with figuring out that identity. In doing so, they may look to pop icons as a way to discover where they see themselves in that celebrity. This can lead to poor performances in school and possibly even bullying and violence... someone who is not up to date with pop culture happenings may have a difficult time understanding how to approach the topic with teens.

The teacher is concerned with how stereotyping and prejudice can interfere with students performance in schools - this is emancipatory. However, during the interview the teacher stated, "I thought [pop culture] could be used in the classroom." Once again, the goal here is to discover practical knowledge for the classroom. Overall, I believe their reasons for the questions posed were both critical and practical (Manfra, 2009a), but candidates did not indicate a commitment to help key stakeholders critically reflect and interrogate structural inequality in schools and schooling to foster empowerment - a key principle of critical AR. Teacher candidates appeared to understand how their topics are connected to broader issues, but wanted to know how to approach their concerns on a local level in their classrooms - decreasing the divide between theory and practice. If this is the case, this finding may indicate two things. Teacher candidates' need to feel empowered about critical issues in education before they broach the topic with other key stakeholders or they see changing their own practice as an easier path to social justice. In the next section, I explore candidates' reported actions taken during and after the AR course to understand how the actions reflect critical AR.

\section{Democratic Practices}

During interviews and in their final papers, eight out of ten teacher candidates reported taking action that created change within or outside the classroom. The teacher whose project 
examined teachers' views of curriculum reported no actions related to the AR project due to her position in the school at the time of the study (i.e. she was an intern). In other words, the candidate felt she lacked the power necessary to create change. This issue, real or imagined, must be addressed with candidates if we expect them to do this work long-term. The candidate who did not pursue teaching stated in the final report, "I was firmly rebuffed by an impenetrable wall of silence" during interviews with principals about budgets in their district. Due to this challenge, the candidate stated during our follow-up interview "I reached out to the Commissioner and I have names of people to reach out to. I just got a little bit tired and am taking a break from the whole thing.” This example can help teachers understand the risks and challenges of being change agents, but also be used to teach them how to strategize when obstacles arise during the inquiry process.

The theme that emerged from the actions the other teachers reported was providing key stakeholders (e.g., students, parents, teacher candidates) with more choice (e.g., interests incorporated into curriculum) or voice (e.g., included in decision-making) in the teaching and learning process (Morrison, 2008). This theme reflects one of the principles of critical ARencouraging democratic practices in schools (Manfra, 2009a). In AR it is critical that the needs of those who are affected by the issue examined or who can affect the outcome of the process be involved (String, 2008). Giving key stakeholders voice and choice in the teaching and learning process is one way of honoring those who are in less powerful positions in the school system (Morrison, 2008). The following examples illustrate how teachers' reported actions reflect this principle.

In the first two examples that follow, the teachers relinquished some of their control in their classrooms to involve students in the teaching and learning process. This action is more 
responsive to the needs of students and may help teachers develop stronger relationships with students (Gay, 2010). The middle school teacher who explored how pop culture influences students' identities, wrote in his final report about how he planned to use students' interests in the curriculum:

This project inspired me to try a new end-of-the-year project where students pick a song and present its meanings to the class. This gives students an opportunity to think about something that is important to them and link [it] to the class. It [can] enhance students' critical thinking. Several students are already very excited about it, as it is one of the few projects where the student is completely in charge of picking the topic.

When I interviewed the teacher, he elaborated on his actions taken, including how he used a popular song to introduce the book, The Outsiders, to help students make connections:

I used something that Katy Perry had sung about being an outsider and that's how it kind of started in the book and I definitely use a lot more in terms of relating things to TV shows and when I teach persuasive writing, which I'm doing right now...I just did an activity today and we looked through newspapers and you find ways in which people persuade you through a newspaper. Definitely I do a lot more in terms of using what they find popular or find important.

In their final report, the team who explored gender differences in classroom participation among ELLs wrote about the actions they planned to take in their classrooms:

Since female ELLs cannot exist in a vacuum, we need to create equitable, social justice school environments in order to equip these young women with the confidence and belief in self to participate in a democratically principled society. By modeling a classroom community in which opinions are negotiated and validated, we can level the playing field 
with male peers, as well as establish a mutual respect for each other. A belief that the social curriculum is as important as the academic curriculum will help support the development of a gender-equal environment in which academic access for males and females, ELLs and mainstream students is facilitated.

When asked during the interview what actions had been taken related to the project one of the teachers provided an example of how she incorporated students' voices in the teaching and learning process. A year after enrolling in the AR course, the teacher decided to implement the AR process again with her students when several approached her about bullying in the school. The teacher described why she decided to teach students the process of inquiry to determine how to address the issue:

We received a new student in the middle of the year and he had a whole different idea about how things should go and the kids were complaining about him. So one day we sat down and talked about what we could do about it. We talked about what we did earlier in the year. So we talked about making a survey together. They actually created it and everyone took it and wrote their answers down and we totaled up the responses. We talked about what that meant if this number of students felt this way about this, or this number of students felt this way about that. Was it a problem or wasn't it, and then we talked about what we could do about it and what resources we had in the school. It was their idea to ask the school counselor to come in to talk about bullying...so it was very empowering. They didn't have to stand by and watch other people get hurt.

This example is significant in that it reflects the proposed actions the teacher wrote in the final report even though the issue is different from the original topic. First, the teacher incorporated a democratic process to problem solving that included the student who was identified as the bully 
so that everyone had a voice in the process. Secondly, students' opinions were negotiated and validated when they developed the tools for inquiry and made the decision to bring in the school counselor. Third, the teacher taught the students a process for change that was collaborative, provided them with an alternative way to respond to bullying, and showed them that they can create change. The teacher could have taken an authoritarian approach toward this issue by punishing the bully herself. Instead, the teacher shared the power of decision-making with the students.

In the final example, the team that explored Spanish-speaking parents' understanding of standardized testing worked with two other elementary teachers to create a Developmental Reading Assessment (DRA) Information Station. This action was taken based on the findings from their study that indicated that parents lacked knowledge about the DRA. They stated, "We believe that if the parents are aware of what level their child is on and what level they are supposed to be on, then they will be able to work with the teachers and their children to help improve their reading comprehension." The station included definitions and examples of different DRA readings levels and was posted in English and Spanish during the third marking period report card conferences. In addition to the information station, the researchers and teachers wrote a DRA communication letter that was sent home to all parents of students in first through third grade after each DRA testing session (i.e. three times a year). During the interview, one of the teachers described how the project influenced her communication with parents throughout the school year now that she has her own classroom:

I think the project helped me see, one, how important communication with parents is at home. At the beginning of the year I send them a letter where I send them my email. I call each parent or send a note home during the year. Having 100 students, it's difficult, 
but doable. I also try to make it clear with parents and student[s] what we are going to [do] in the course and how things are going. I even have parent contact [where] I'm emailing them every week about their student's progress. So I think that really impacted me seeing how much parent support can impact the learning of the student. That really changed my practice.

This example went beyond practical AR. The teachers examined a social and cultural issue that may affect schooling and took action to empower the parents with information they believed could increase their role in their children's education and improve their chances for academic success. While they did not discuss with parents how standardized testing could reproduce structural inequality, the change they created went beyond the immediate need of one teacher and improving technical and practical knowledge.

\section{Discussion and Implications}

The goal of this inquiry was to explore how teacher candidates' AR projects reflect critical AR — indicating a commitment toward change agency and promoting its emancipatory goals. Overall, the findings are mixed. Teacher candidates did begin to explore how sociocultural factors may impact their students' academic success. This finding may indicate that teacher candidates were beginning to understand their students in more complex ways. Developing a sociocultural consciousness can help teachers close the divide between them and their students (Nieto \& McDonough, 2011). However, for this skill to be fully realized teachers must begin examining how their own sociocultural identities, worldviews, biases, and prior experiences have influenced their philosophy of teaching and learning (Nieto \& McDonough, 2011). I believe this is the first step necessary to become a change agent. The implication is to ask teacher candidates to critically reflect on these issues directly when exploring what factors drove the topics posed 
for their studies. I will be explicit about this in the AR course and hope candidates will consistently practice this skill in their classrooms.

The actions teacher candidates reported showed a developing commitment toward incorporating the voices of key stakeholders into the teaching and learning process. One of the principles of teaching for social justice is for teachers to develop respectful relationships with students, parents, and their communities to support students' learning (Gay, 2010). The working principles of AR, participatory and inclusion, may in part explain this finding. Stringer (2008) argues that it is "normal practice for professional practitioners to take responsibility for all that needs to be done in their sphere of operation" (p. 35). As part of the process of conducting research, teacher candidates were strongly encouraged to incorporate key stakeholders in their inquiries. Including the voices of key stakeholders into the teaching and learning process and in their AR projects might indicate an increased commitment toward using democratic practices in their classrooms. The Nigerian proverb states that it takes a village to raise a child. Teaching is a community practice. Teachers building effective, reciprocal relationships that support students' learning, rather than working against parents and communities who have been historically marginalized, is one indication of them becoming change agents. The implication here is to help teacher candidates move beyond "individual heroism" (Grant \& Agosto, 2008) to working collaboratively with parents and communities so that educational change can be sustainable. While some candidates did critically reflect about structural inequality in schools and schooling, none indicated that they explored structural inequality with key stakeholders as part of their AR projects. In addition, candidates indicated critical concerns about relevant educational issues in their papers and interviews, but the reasons for their topics were more practical than emancipatory. While I believe candidates' reasons can be both practical and emancipatory, the 
majority were not explicit about social change as a specific goal for their research. There are a number of reasons that may explain these findings. First, the candidates may have felt a lack of support by those in positions of power (Villegas \& Lucas, 2002). For example, one teacher stated that while her principal did support her AR project as a course requirement, "there was also an understanding that this isn't the norm (teachers conducting research) for our school. That was very explicit." Also, the principles of critical AR are not promoted as part of standards-based and accountability mandates (Dover, 2013). So, teachers and administrators may not see helping key stakeholders critically reflect and interrogate structural inequality in schools and schooling or social change as integral to their work. Furthermore, factors such as "hierarchical and bureaucratic nature of the educational system, time pressure, insufficient opportunities for collaboration with others, lack of personal understanding of oppression and empathy for those who are oppressed, and despair that change is possible" (Villegas \& Lucas, 2002, p. 24) work against teachers becoming change agents.

One additional factor that may play a role is teachers' different conceptualizations of social justice and change agency. All of the teacher candidates were able to describe how their AR projects were examples of social justice advocacy when asked. Since all were novice teachers (except one) and see teaching as their primary role, they may believe any changes made in the classroom to improve student learning is emancipatory and being a change agent. Kinsler (2010) argues all forms of educational AR are emancipatory if they improve the lives of marginalized groups in schools. The implication for teacher preparation programs is to be more specific about learning outcomes that reflect a social justice goal (Kaputska, Howell, Clayton, \& Thomas, 2009). This point is important now that our department is in discussions to require all of our teacher candidates to complete an AR course. In addition, I believe teacher candidates should 
be involved in developing the traits with teacher educators that indicate growth and development toward learning outcomes with a social justice focus. This would help candidates be clear about what they are working toward in a practical sense. I recommend future research explore what commitment toward change agency might look like for teacher candidates at different transition points in their teacher education programs and during their induction years. In other words, what happens between awareness of social injustice and taking action? How do we teach them differently throughout this process, and how do we effectively assess their growth and development?

Moreover, as I compare the themes to the framework used for this study, I began to wonder if students' AR projects showed one or two aspects of critical AR, is that enough evidence to state that teacher candidates are becoming change agents? I argue that increasing teachers' sociocultural awareness and being more reflective about their practice is not enough. Action must occur and that action must be transformative for students in order for it to be identified as emancipatory. The implication is to have teacher candidates explain how the changes made as a result of conducting AR is transformative for the students, parents, and communities involved. However can we as teacher educators expect that action after one semester and during their first attempt at conducting AR? I will be more explicit about this expectation with candidates in my course and discuss how it is linked to course and departmental objectives.

Finally, research that explores teachers' experiences with conducting AR and how it may deepen their commitment toward change agency is beginning to emerge. In this study, I provided a framework to gauge how candidates' AR projects reflect critical AR and assess their commitment toward change agency. In addition, I gave details of my practice to help teacher 
educators who want to prepare teacher candidates for social justice work in schools. My findings show candidates' developing commitments toward change agency in one course during one semester. I recommend future studies explore the long-term influence of conducting AR on teachers' practice and commitments toward agency that include observations of their change agency activities inside and outside the classroom. Furthermore, I recommend similar studies conduct interviews within a semester of course completion in addition to follow-up interviews a year later to explore the sustainability of any reported changes made as a result of conducting AR. Additionally, we need more studies that explore the pedagogical practices in AR courses to help teacher educators design effective experiences for teacher candidates (Grossman, 2005). I believe this reflective process will continue to improve our practice when preparing teacher candidates for social justice advocacy. 


\section{References}

Boczer, A., Wrinn, C., \& Nash, K. (2013). 2012 - 2013 Fact book.

http://www.fairfield.edu/media/fairfielduniversitywebsite/documents/about/ir_fact_book_pri nt2012-13.pdf

Burrell Storms, S. (2013). Preparing teacher candidates for social justice advocacy: Am I walking my talk? Multicultural Education, 20(2), 33-39.

Carr, W., \& Kemmis, S. (2009). Educational action research: A critical approach. In S. Noffke \& B. Somekh (Eds.), Handbook of educational action research (pp. 74-84). London: SAGE.

Charmaz, K. (2010). Grounded theory: Objectivist and constructivist methods. In W. Luttrell (Ed.), Qualitative educational research: Readings in reflexive methodology and transformative practice (pp. 183-207). New York: Routledge.

Church, K. L. (2010). A course exploration: Guiding instruction to prepare students as change agents in educational reform. InSight: A Journal of Scholarly Teaching, 5, 15-26.

Cochran-Smith, M., \& Lytle, S. L. (2009). Inquiry as stance: Practitioner research for the next generation. New York: Teachers College Press.

Colón-Muñiz, Brady, \& SooHoo, (2010). What do graduates say about multicultural teacher education? Issues in Teacher Education, 19(1) 85-108.

Creswell, J. W. (2007). Qualitative inquiry \& research design: Choosing among five approaches. Thousand Oaks, CA: Sage.

Daoud, A. M. (2010). Providing equitable instruction for high school English learners: How teacher candidates define and enact social justice. International Journal of Humanities and Social Science, 1(7), 14-22. 
Dover, A. (2013). Getting "up to code" : Preparing for and confronting challenges when teaching for social justice in standards-based classrooms. Action in Teacher Education, 35, 89-102.

Falk, B., \& Blumenreich, M. (2005). The power of questions: A guide to teacher and student research. Portsmouth, NH: Heinemann.

Furman, M., Barton, A. C., \& Muir, B. (2012). Learning to teach science in urban schools by becoming a researcher of one's own beginning practice. Cultural Studies of Science Education, 7, 153-174.

Gall, J. P., Gall, M. D., \& Borg, W. R. (2007). Applying educational research: A practical guide (8th ed.). Boston: Pearson Education.

Gay, G. (2010). Culturally responsive teaching: Theory, Research, and Practice ( $2^{\text {nd }}$ Ed.). New York: Teachers College Press.

Grant, C. A., \& Agosto, V. (2008).Teacher capacity and social justice in teacher education. In M. Cochran-Smith, S. Feiman-Nemser, \& D. J. McIntyre (Eds.), Handbook of research on teacher education: Enduring questions in changing contexts (3rd ed., pp. 175-200). New York: Routledge.

Grossman, P. (2005). Research on pedagogical approaches in teacher education. In M. CochranSmith \& K. M. Zeichner (Eds.), Studying teacher education: The report of the AERA panel on research and teacher education (pp. 425-476). Mahwah, New Jersey: Lawrence Erlbaum Associates.

Guba, E. G., \& Lincoln, Y. S. (1982). Epistemological and methodological bases of naturalistic inquiry. Educational Communication and Technology, 30(4), 233-252.

Harris, A. S., Bruster, B., Peterson, B., \& Shutt, T. (2010). Examining and facilitating reflection to improve professional practice. Lanham, Maryland: Rowman \& Littlefield. 
Jacobs, J., Yamamura, E., Guerra, P. L., \& Nelson, S. W. (2013). Emerging leaders for social justice: Negotiating the journey through action research. Journal of School Leadership, 23, 91-121.

Kane, R. G., \& Chimwayange, C. (2014). Teacher action research and student voice: Making sense of learning in secondary school. Action Research, 12(1), 52-77.

Kapustka, K. M., Howell, P., Clayton, C. D., \& Thomas, S. (2009). Social justice in teacher education: A qualitative content analysis of NCATE conceptual frameworks. Equity \& Excellence in Education, 42(4), 489-505.

Kemmis, S. (2006). Participatory action research and the public sphere. Educational Action Research, 14(4), 459-476.

Kinsler, K. (2010). The utility of educational action research for emancipatory change. Action Research, 8(2), 171-189.

Ladson-Billings, G. (2011). Asking the right questions: A research agenda for studying diversity in education. In A. F. Ball \& C. A Tyson (Eds.), Studying diversity in teacher education, (pp. 385-398). Lanham, MD: Rowman \& Littlefield.

Manfra, M. M. (2009a). Action research: Exploring the theoretical divide between practical and critical approaches. Journal of Curriculum and Instruction, 3(1), 32-46.

Manfra, M. M. (2009b.). Critical Inquiry in the Social Studies Classroom: Portraits of Critical Teacher Research. Theory and Research in Social Education. 37(2), 156-192.

Martin, R. J. (2005). An American dilemma: Using action research to frame social class as an issue of social justice in teacher education courses. Teacher Education Quarterly, 32(2), 522. 
McNiff, J., \& Whitehead, J. (2010). You and your action research project ( $3^{\text {rd }}$ Ed.). New York: Routledge.

Morrison, K. A. (2008). Democratic classrooms: Incorporating student voice and choice in teacher education courses. Educational Horizons, 87(1), 50-60.

National Center for Education Information. (2011). Profile of teachers in the U.S. 2011. Washington, DC: Author

Planty, M., Hussar, W., Snyder, T., Kena, G., KewalRamani, A., Kemp, J., Bianco, K., Dinkes, R. (2009). The Condition of Education 2009 (NCES 2009-081). National Center for Education Statistics, Institute of Education Sciences, U.S. Department of Education. Washington, DC.

Nieto, S, \& McDonough, K. (2011). "Placing equity front and center" revisited. In A. Bell \& C. Tyson (Eds). Studying diversity in teacher education (pp. 363-384). AERA and Rowan \& Littlefield: Lanham, MD.

Price, J. N., \& Valli, L. (2005). Preservice teachers becoming agents of change: Pedagogical implications for action research. Journal of Teacher Education, 56, 57-72.

Razfar, A. (2011). Action research in urban schools: Empowerment, transformation, and challenges. Teacher Education Quarterly, 38(4), 25-44.

Sowa, P. A. (2009). Understanding our learners and developing reflective practice: Conducting action research with English language learners. Teaching and Teacher Education, 24, 10261032.

Stringer, E. (2008). Action research in education ( $2^{\text {nd }}$ ed.). Upper Saddle River, NJ: Pearson. Villegas, A., \& Lucas, T. (2002). Preparing culturally responsive teachers: Rethinking the curriculum. Journal of Teacher Education, 53(1), 20-32. 


\section{Appendix A \\ Interview Protocol for Teacher Researchers}

\section{Course Details}

1. What did you know about action research before your enrolled in the course?

2. What did you the learning goals were for the course?

3. What were your feelings about the course assignments?

\section{Conducting Action Research during Course}

4. What was the topic of your research project? Why did you select that topic?

5. Did you see your study as an example of advocating for social justice? If so, in what ways?

6. What was conducting action research like for you?

7. What were the challenges and rewards of the process?

\section{Actions after Course}

8. Did you continue your project after the action research course ended? Why or why not?

9. Was your school supportive of this type of practice? If so, how? If no, why?

10. What actions did you take as a result of conducting action research?

11. Is there anything you think I should know that I did not ask? 